\title{
交感神经对外周伤害性感受器的 传出抑制作用
}

\author{
胡三觉 胡家俊 \\ (第四军医大学生理教研空,西安)
}

外周感受器的活动受到中枢的传出控制曾有过一些报道 ${ }^{[1-3]}$. 交感神经对感受器的传出 到响也引起人们的注意, Loewenstein ${ }^{[1]}$ 及 Chernetski ${ }^{[5]}$ 观察到交感神经对皮肤触觉感受器有 易化作用. 近年来，Santini 等发现交感神经分布到感觉神经末梢周围，刺激交感神经可抑制 触觉小体诱发的传人冲动向. 但是, 关于外周伤害性感受器是否受中枢的传出控制尚末见报 道. 本实验用钾离子透入法刺激大鼠尾部皮肤, 引导并统计其诱发的背根和尾神经传人冲动 数作为伤害性感受器兴奋的指标, 观察中枢和交感神经对外周伤害性感受器的作用.

\section{一、方 法}

实验动物为 130 只大鼠. 在氮醛糖一尿醌麻醉下, 暴露 $\mathrm{L}_{5} \sim \mathrm{S}_{4}$ 椎管内的宵髓根丝, 或在尾 根部分离一侧尾神经. 有关手术完成后, 大部分实验在箭毒麻㾇下进行, 部分实验维持上述麻 醉状态。

背根和尾神经传入冲动的引导和计数：从支配尾部的背根中分离一条细支，切断近脊䯣 端，把外周端悬挂在一对白金丝电极上. 引导尾神经时,则把尾神经的近中枢端剪断，外周端 悬挂在白金丝电极上. 然后经放大器连接示波器、脉冲记数装置和录音机. 按实验程序可统 计出每 5 秒的传入冲动数,录制的传入冲动还可输至电子计算机分析.

腰鲳部交感干的切断与刺激: 在腹部腔静脉背侧仔细分离一段交感干，把丝线穿过交感 干做成小环，线的另一端引至切口外，实验时可随时拉断交感干．刺激时，在腹腔内做一埋藏 电极或者通过腹壁的特制窗口用保护电极挂住交感干. 刺激频率每秒 20 次, 强度约 5-10 伏, 时间 5 分钟.

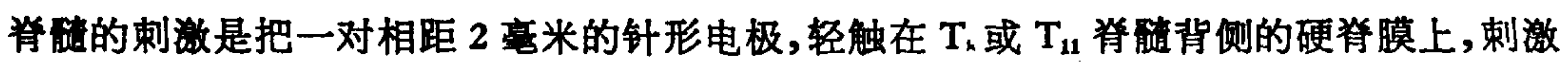
频率每秒 100-300 次, 强度 10-15 伏, 时间 5 分钟. 为了从尾部动脉给药, 将一细塑料管由 一侧股动脉插人至腹主动脉分叉处,再通过套管逆行注射,可使药液顺动脉分布到尾部. 钾离 子透人法，触觉刺激以及尾部皮温的测定等方法见前文报道 ${ }^{[7]}$.

\section{二、绍 果}

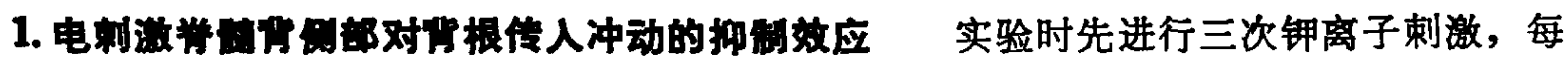
次间隔 10 分钟,然后电刺激脊酷背侧部 5 分钟,接着继续进行钾离子刺激, 直到诱发的背根冲

本文1981年2月9日收到。 
动数基本恢复为止. 以刺激脊髓前的三次钾离子刺激诱发的背根冲动的平均数作为对照 值, 分别求出刺激脊髓后各次钾离子刺激诱发的背根冲动数与对照值相比的百分数, 以判定刺激 脊骴的效应.

在 9 只大鼠电刺激 $\mathrm{T}_{8}$, 有 8 只的背根冲动数受到显著抑制. 停剌激后的 5 分钟内, 冲动 平均数减少到对照值的 $66 \%$ ，经过 30 多分钟才恢复到原水平. 图 1 为一次实验的背根冲动 密度序列分布. 为了避免刺激脊髓时兴奋上行传入脑髓可能造成的影响, 另在 47 只切断 $\mathrm{T}_{10}$ 的大鼠上刺激了 $\mathrm{T}_{13}$, 其中 36 只出现显著抑制效应, 冲动平均数可减少到 $61 \%$, 后效应也有 30 多分钟 (图 2). 实验结果表明, 刺激脊髄背侧部可使外周伤害性感受器的兴奋性受到抑 制.

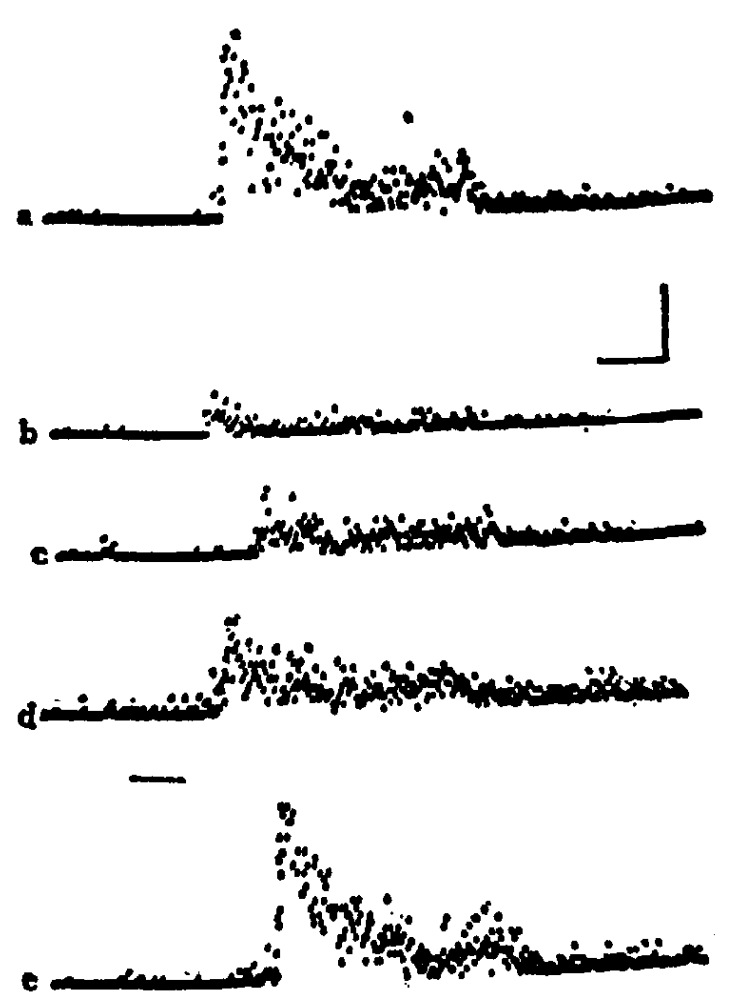

图 1 电刺激 $T_{8}$ 的背根冲动密度序列直方图 $a$ 对炤，b、c、d 和e 分别为停刺激后 $1 、 10 、 20$ 和 30 分. 校正: 横坐标为时间 1 秒，纵坐标为单位时间(20 毫秒)内 的冲动数 ( 5 个冲动)
此外,在 35 只大鼠切断 $\mathrm{T}_{10}$ 后, 有 28 只铎 离子刺激诱发的背根冲动数比切断前显著增 多. 切断 $T_{10}$ 后的第 $10 、 20$ 和 30 分的背根冲 动平均数分别为切断前对照值的 $134 \%, 142 \%$ 与 $154 \%$ ，提示在生理状况下，高位中枢通过 脊傕对伤害性感受器的传出抑制有紧张性的特 点.

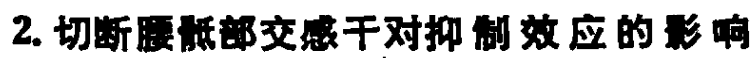
为了分析脊膸的抑制效应是通过哪条途径 传出，作了以下几组观察：在 5 只大鼠切断支

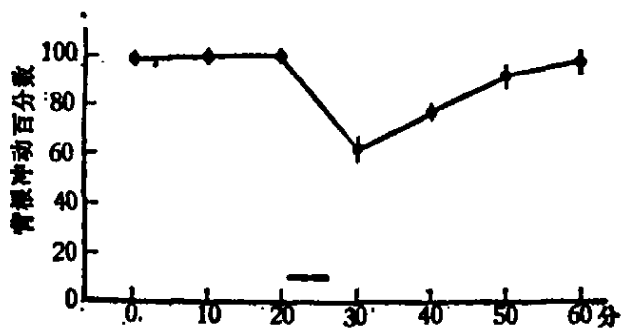

图 2 电刺擞 $T_{11}$ 对背根冲动的抑制效应 (36 例) 各圆点上的垂直线为标准误，图下方栱线为刺激时间

眍尾部的脊䯕背根和腹根，没有看到对抑制效应有明显影响; 切除两侧肾上腺在 3 小时内也没 有明显影响. 在 5 只大鼠切断支配尾部的腰骶部交感干,脊髓的抑制效应则基本消失.切断交 感干前,刺激 $T_{11}$ 后的 $1 、 10 、 20$ 和 30 分的背根冲动平均数分别为对照值的 $61 \% 、 79 \% 、 94 \%$ 和 $97 \%$ ，切断交感干之后则分别为 $98 \% 、 96 \% 、 98 \%$ 和 $102 \%$ 。 由此可见交感神经可能是脊 筑抑制效应的主要传出途径.

切断交感干后，钾离子刺激诱发的背根冲动数也有增多的倾向. 在 6 只脊髓完整的大鼠 切断交感干后，除 1 只背根冲动数变化不明显外，其余 5 只的冲动数在切后 10 分钟左右都增 加到切断前的 110-130\%，说明交感神经对伤害性感受器的抑制也具有紧张性的特点.

3. 刺激原低部交感干对传入冲动的抑制效应 在 8 只大鼠进行了 13 次刺激交感干的 
实验,其程序与上述类同,只是钾离子刺散的间隔改为 2 分钟(有的为 1 分钟). 结果除 1 次在 刺数交感干后背根冲动数增多外，其余 12 次均有显著抑制效应。停刺激后的第 1 分钟，背根 冲动平均数减少到对照值的 $40 \%$ ，经过 20 分钟左右才逐渐饭复(图 3). 为了直接观察交感神 经传出纤维对伤害性感受器的作用,另在 16 只大鼠测定了刺激交感干外周端对钾离子刺激诱 发尾神经传入冲动的抑制效应. 如图 4 所示,刺激交感干的第 1 分钟,冲动数便开始减少，到 刺激的第 5 分钟,冲动数降到最低,为对照值的 $57 \%$ ，停刺激后经过 6 分钟便基本饭复. 图 5 为一次实验过程各次尾神经冲动的密度序列分布. 当用 $2 \%$ 利多卡因阻滞交感干外周端后， 则不再显示抑制效应. 这一结果不仅表明交感神经的传出纤维对外周伤害性感受器的兴奋性 有显著的抑制效应，而且看出直接刺激交感干外周端的抑制后效应时间相当短.

在同体进行比较的实验中发现，刺激交感干外周端对触压尾部皮肤诱发的尾神经冲动也 有一定的抑制效应，不过其抑制的程度比对钾离子刺潡诱发冲动的抑制要弱得多，抑制作用的 时间也短得多.

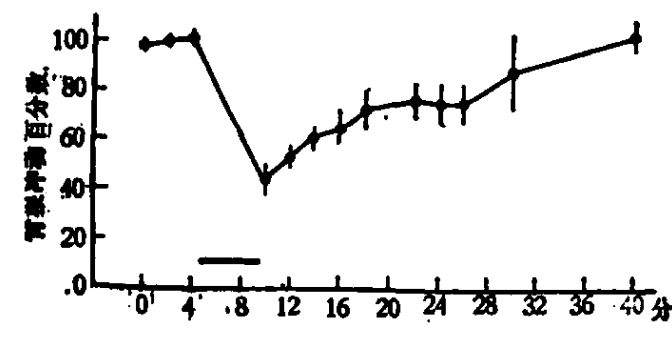

图 3 刺激委眡部交感干对背根冲 动的抑制效应 (12 例)

各回点上垂立线为标准误，因下方横线为刺数时间

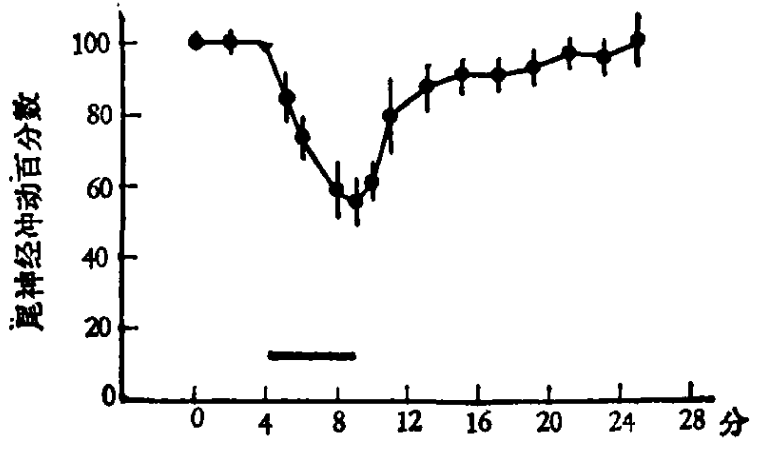

图 4 刺激腰鲳部交感干外周端对尾 神经冲动的抑制效应 (16 例)

（注解同图 3)

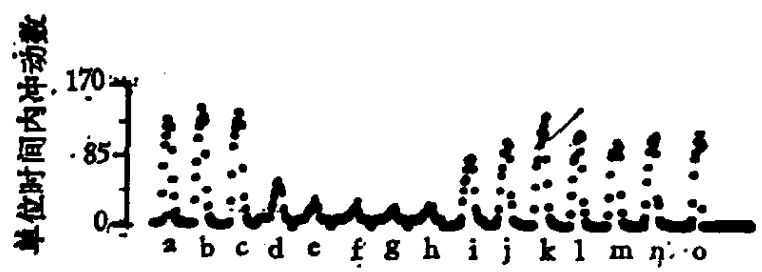

图 5 刺激交感千外周端对尾神经冲动的抑制

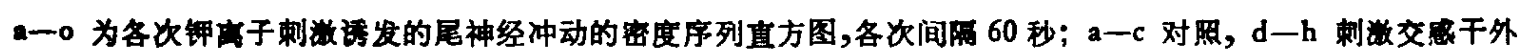

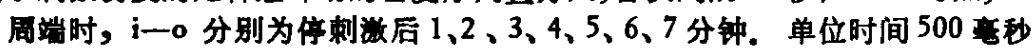

在刺激交感干时,尾部皮温也随之降低,说明尾部血流有所减少. 为了分析交感神经对外 周伤害性感受器的抑制效应是否可能由于外周血管收缩, 减少了对感受器的血流供应所致, 我 们在向尾部动脉注人酝罗拉明( $0.4-0.6$ 毫克/5-7 分钟)的同时再刺激交感千. 此时尾温不 仅不降低反而随着酚罗拉明的缓慢注人而上开, 表明尾部血管处于扩张状态,而钾离子刺激诱 发的尾神经冲动数仍然明显减少. 在停止刺激交感干和注药后, 冲动数逐渐增多到对照值水 平, 尾温却降低并恢复到注药前水平(图 6). 这一尾温与冲动数交叉变化的现象说明即使消 除了缩血管作用,交感神经仍可显著抑制伤害性感受器的兴奋性.

4. 拟交感药对传人冲动的抑解效应在 2 分钟内向腹主动脉注人 0.5 毫升生理盐水,对 


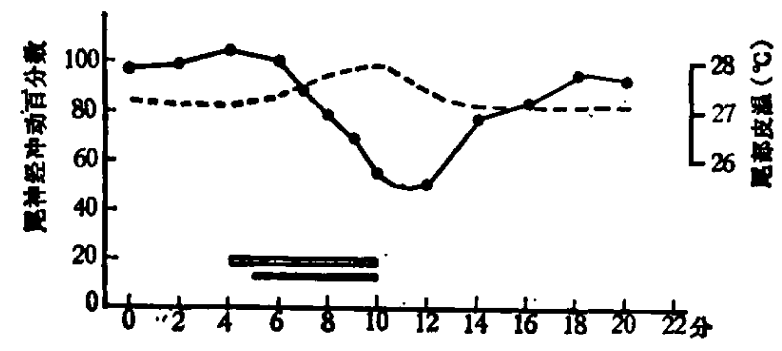

图 6 酚妥拉明对交感神经效应的影响

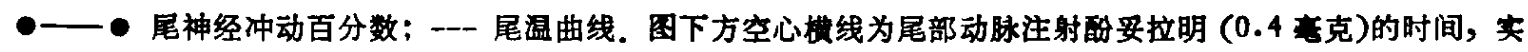

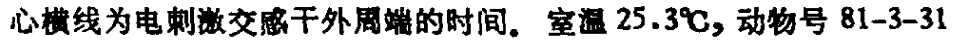

钾离子刺激诱发的背根冲动数没有影响; 注人 0.5-2.5 微克肾上腺素(溶于 0.1 毫升生理盐水 中)却可使冲动数显著减少. 在 5 只大鼠的 7 次实验中看到, 注药后 4-8 分的抑制效应最显 著, 冲动平均数减少到对照值的 $62 \%$ ，经过 30 分钟左右才基本恢复. 把同剂量的肾上腺素从 股静脉注人,背根冲动数却没有明显变化.

在 6 只大鼠进行 9 次去甲肾上腺素的动脉注射 (10一30 微克/0.1 毫升生理盐水), 全都出 现显著抑制效应. 多数在注药后 2-4 分的抑制效应最明显, 背根冲动数减少到 $70 \%$ ，经 10 分钟左右即恢复. 把同剂量的去甲肾上腺素作股静脉注射也没有出现明显的抑制效应. 上述 结果说明,肾上腺素和去甲肾上腺素对伤害性感受器的抑制是外周周部作用，并非全身效应的 反映.

此外, 向动脉内注人具有舒张血管作用的异丙肾上腺素 (10-50 微克)，4-6 分钟即可使 背根冲动数减少到 $70 \%$ 左右, 有效时间约 20 多分钟. 上述拟交感药的抑制效应在尾以尾神 经传入冲动为标的实验中也可得到重复.

\section{三、讨 论}

本实验的结果表明, 中枢对外周伤害性感受器存在抑制作用, 其传出的主要途径是交感神 经. 这一传出抑制不仅具有紧张性的特点, 还对伤害性感受器具有相对的特异性. 至于交感神 经的这一抑制作用是否可能由于外周血管收缩, 局部血流减少所致, 是值得深入分析的. 根据 如下初步的实验结果得到的印象，该抑制效应与血管收缩没有直接的关系. 首先, 向尾部动脉 注入酚妥拉明阻断 $\boldsymbol{\alpha}$ 受体, 消除交感神经的缩血管作用后, 刺激交感干仍可显著抑制钾离子刺 激诱发的传人冲动数, 说明抑制效应与血管是否收缩无关. 第二, 我们曾经临时阻断尾部血流 5 分钟，尾温立即显著降低，背根冲动数却减少不明显，比刺滶脊符的抑制效应弱得多. Lynn 等也观察到阻断局部血流 8-12 分钟, 对伤害性感受器的传认冲动没有显著影响 ${ }^{[8]}$. 这就说 明短时间减少局部血流不会成为抑制伤害性感受器的主要原因. 第三, 刺激交感干对触觉感 受器的传入冲动没有明显抑制, 说明在本实猃条件下局部供血的减少尚不足以显著影响感受 器的兴奋性. 否则, 首先受到显著抑制的应该是触觉感受器而不是伤害性感受器. 第四, 具有 舒张血管作用的异丙肾上腺素也可导致传人冲动的减少, 进一步说明抑制效应并非必需血管 收缩. 据此,我们推论在伤害性感受器水平可能存在某种与血管无关的交感抑制机制.

有些作者在全身给药的实验中观察到拟交感药的镇痛作用, 并认为这是由于药物的中枢 作用所致, 与外周作用无关 ${ }^{[9-11]}$. 但是这类实验多是观察动物整体痛反应的改变, 难以明确区 
分药物的中枢与外周作用. 本实验通过动脉局部给药观察到拟交感药可显著抑制伤害性刺激 诿发的背根或尾神经的传入冲动，从而表明其外周抑制作用可能构成镇痛的一个环节。这一 事实也有利于上述在外周伤害性感受器水平存在交感抑制机制的推想.

致谢：本研究在王复周数授指导下进行，陈敏和罗彦农同志参加部分实验，谨表感谢。

[1] Hunt, C. C. \& Kuffler, W., J. Physiol., 113(1951), 283-297.

[ 2 ] Galambos, R., J. Nourophysiol., 19(1956), $424-137$.

[ 3$]$ Granit, R., J. Neurophysiol., 18(1955), 388-411.

[4] Loewenstein, W. R., J. Physiol, 132(1956), 40-60.

[5] Chernetski, K. E., J. Nourophysiol., 27(1964), 493-515.

[ 6 ] Santini, M. et al., J. of Cell Biol., 63(1974), 298a.

[ 7 ] 胡三管, 第四军医大学学报, 1(1981), 24-29.

[8] Lynn, B., J. Physiol., 287(1979), 493-507.

[9] Heller, B. et al., Krperientia, 24(1968), 804-805.

[10] Major, C. T. \& Pleuvry, B. T., Brit. J. Pharmacol., 42(1971), 512-521.

[11] Rothballer, A. B., Pharmacol. Rev., 11(1959), 494-547. 